\title{
Strategies for developing a sustainable learning society: An analysis of lifelong learning in Thailand
}

\author{
Post Print
}

ABSTRACT: Today's world may be characterised as the dawn of the new millennium of the learning society, where knowledge is considered as a country's most valued asset and primary source of power. In the increasingly intense competition among international communities, Thailand has been respected for advancing the concept of transforming communities, cities and regions into learning societies engaged in a sustainable development strategy which promotes the continual learning of individuals - the smallest unit of society. The learning society approach aims to balance economic, social, natural and environmental aspects and resources of society; and is transforming the Thai people into knowledge citizens and knowledge workers. The underlying legislation carries stipulations concerning lifelong learning, educational enhancement and global competitiveness aimed towards developing appropriate manpower to move the society towards sustainable happiness as compared and contrasted with maintaining the "status quo". This article portrays the current situation of lifelong learning and education in Thailand; analyses and synthesises five best-practice learning society case studies and proposes guidelines for developing a sustainable learning society.

PUBLISHER'S VERSION:

https://link.springer.com/content/pdf/10.1007\%2Fs11159-014-9444-y.pdf

CITATION: Henschke, J. A. "Observations of the Possible Influence of Andragogy on the Economies of World Nations." International Education and the Next-Generation Workforce: Competition in the Global Economy. , 2013. SCOPUS, www.scopus.com, doi:10.4018/978-1-4666-44984.ch007. 


\section{Introduction}

In the 21st century, global demands for economic competitiveness and social cohesion, the application of information technologies for interactive communication and associated learning, and the growing awareness of the need for lifelong learning strategies all combine to ensure sustainable economic and community development. Ever since the Organisation for Economic Cooperation and Development (OECD) funded a project to create "Educating Cities" in the 1970s (Longworth 2006), the idea of developing "Learning Societies" has expanded throughout the world. ${ }^{1}$ According to the International Association of Educating Cities (IAEC), 474 cities in 36 countries have joined since its foundation in 1994 and are actively participating in the concept (IAEC 2012). Among these learning cities and 36 countries are Barcelona in Spain; Stockholm in Sweden; Munich in Germany; Montreal in Canada; Dublin in Ireland; Delft in the Netherlands; Birmingham in the United Kingdom; Edinburgh in Scotland; Victoria in Australia; and Espoo in Finland, and countries in the Asia-Pacific Region such as Singapore, China, Japan and Korea (Cisco 2010; Faris 1998, 2006; Kwon and Schied 2009; Ergazakis et al. 2006).

These cities have influenced the development of the learning society. Even though the concept of the leaning society is a relatively new one, progress is under way, perhaps spurred by international positions and policies, such as the World Development Report 1998-1999 on Knowledge for Development (World Bank 1998), UNESCO's World Report, Towards Knowledge Societies (UNESCO 2005), and a wide range of European Union activities (Morris and Cranford 2007). A number of countries (e.g., New Zealand, Ireland, Poland and China) have formulated strategies to build learning societies.

Characteristics of a learning society generally include the idea of a group of individuals residing within one locality, or an agency or a community engaged in single or multiple matters simultaneously. They are involved in preservation, nourishment, rehabilitation, protection, promotion, assistance, development and distribution, using information technology, learning resources, local wisdoms and knowledge which allow members of the group or society to create, share and use knowledge, common skills and opinions with fellow members of the same and other communities on a regular lifelong basis. A learning society generates new knowledge and appropriate knowledge management systems, as well as making the best life decisions for the prosperity and 
wellbeing of its people (Charungkaittikul 2011a). A learning society is comprised of learners, learning providers, learning resources, wisdom/knowledge, lifelong learning activities, learning climates, learning networks, knowledge management and learning organisations (Charungkaittikul 2011b).

In Thailand, the legal basis for lifelong learning lies in the Constitution of the Royal Kingdom of Thailand B.E. 2550 (RTG 2007), ${ }^{2}$ the Eleventh National Economic and Social Development Plan B.E. 2555-2559 (2012-2016) (NESDB 2011), the National Education Act B.E. 2542 (RTG 1999), the National Education Act Amendment (Issue 2) B.E. 2545 (RTG 2002), and the Non-Formal and Informal Education Promotion Act B.E. 2551 (ONIE 2008). All of these acts include stipulations concerning lifelong learning, educational enhancement and global competitiveness, with the aim of developing Thai society towards sustainable happiness, balancing economic, social, natural and environmental aspects and resources of society and transforming the Thai people into knowledge citizens and knowledge workers (Dulayakasem 2005). To many people, lifelong learning is a goal in itself, a crucial basis for the personal fulfilment of the individual. Lifelong learning is essential for getting a job, keeping a job, and developing in a job. It must also contribute to enabling working people to cope with periods of unemployment and early retirement and to access and re-access work opportunities. Lifelong learning is at the same time fundamental for society as a whole, as a means of promoting democracy and human rights, solidarity and international awareness and preventing social exclusion (Gelpi 1985).

Current definitions of lifelong learning have been summarised elsewhere (Henschke 2014) as follows: Lifelong learning is a master concept or andragogical principle of continuous and never complete development, changes, and adaptation in human consciousness. This includes learning which occurs partly through deliberate action of non-formal, informal, formal educational systems, but even more as a result of the business of day-to-day living, and may be intentional or unintentional. It includes acquiring greater understanding of other people and the world at large, based on six pillars of learning: learning to know - acquiring appropriate information, comprehending the content subject matter, and employing the instruments of its application in various situations; learning to do - being able to act creatively on one's environment, learning to live together - participating and cooperating with other people in all human activities; learning to be - an essential progression which proceeds from the previous three learning to change - encouraging changes in behaviour to create a more viable and fair society for everyone; and learning for 
sustainable development - making efforts towards sustainability in any field which are built on processes for communicating, learning, and sharing knowledge, engaging people in their multiple roles as individuals, ${ }^{3}$ and as members of communities and organisations.

Two Thai studies by Noppamonton Sibmeunpiam (2003) and Sumalee Sungsri (2005) revealed that Thai public and private agencies remain without an appropriate learning society model developed from the synthesis of knowledge appropriate to the social contexts and aimed at achieving an actual positive paradigm shift for communities in a structured and procedural manner. Similarly, studies from other countries (Longworth and Osborne 2010; Cisco 2010; Su 2007; Laszlo and Laszlo 2007; Lantz and Brage 2006; Casey 2006; Faris 1998, 2006; UNESCO 2005; Longworth 2006; Carrillo 2004; Faris and Peterson 2000; Keating and Hertzman 1999; Yarnit 1998) have shown that while there is a growing interest in learning cities and societies, the field still lacks a consensus regarding description or clarification and appropriate conceptual and methodological frameworks. In addition, the 2005 UNESCO World Report Towards Knowledge Societies emphasised the need to clarify the aims of knowledge societies, align them with paradigms of growth and development, guide them with ethics such as freedom and responsibility, and include within them the means for all to share knowledge (UNESCO 2005).

Our intention in this article is therefore to give an overview of the current situation of lifelong learning in Thailand, to present an analysis and synthesis of best practices and then to propose practical strategies for developing a sustainable learning society. Extensive background to this paper was provided by research studies we conducted recently (Charungkaittikul and Henschke 2011; Charungkaittikul 2011a, b).

\section{The current situation of lifelong learning and education in Thailand}

As mentioned in the introduction, a legal basis for lifelong learning is in place in Thailand. According to the National Education Act (RTG 1999, Sect. 4) and its amendment (RTG 2002), "education" is defined as a learning process for personal and social development through imparting of knowledge, practice and training; transmission of culture; enhancement of academic progress and, using available resources, building a body of knowledge by creating a learning environment and society conducive to continuous lifelong learning. The National Education 
Act defines "lifelong education" as education resulting from the integration of formal, non-formal and informal education so as to facilitate continuous lifelong development of quality of life. Further, the Act prescribes that all learners must have access to formal, non-formal and informal education. Educational institutions, families, communities, community organisations, local administration organisations, the private sector, private entities, social institutions and all relevant parties are required to collaborate in making learning readily available to everyone, regardless of time and location. This involvement of society itself in knowledge management and the development of learning content is key to creating a learning society or a knowledge-based society (RTG 1999, 2002). The National Education Act encourages Thai society to participate in educational management, uninterrupted learning processes and content development, since these are crucial to the creation of a learning society or a knowledge-based society (ibid.). The legislative recommendations are put into actual practice by agencies in all sectors. On 2 December 2003, the cabinet determined five strategies to reform non-formal and informal education:

(1) clearly identify target groups and determine a diverse range of activities which are appropriate for and relevant to the needs of the target groups;

(2) manage knowledge and learning resources;

(3) position the communities as lifelong learning centres;

(4) allocate budget and decentralise authority to the target groups; and

(5) focus on liaison and facilitation of lifelong learning (ONIE 2011b).

The term "lifelong learning" is widely used in different contexts. For the Thai community, lifelong learning shares two main meanings. The first meaning is the education which happens throughout people's lifetime, starting from the first day to the last day of their lives ("cradle to grave"). In addition, lifelong learning under this first meaning is also regarded as being a part of people's daily lives. The second meaning of lifelong learning is a combination of the different systems of Thai education which help people continue to develop their lives (Pichayasathit 2001).

The current situation in Thailand for lifelong learning and education consists of formal, non-formal and informal education. All of these kinds of education are used as tools to develop human capital, especially in terms of knowledge, thinking processes, 
capabilities, behaviours, values, attitudes and virtue. Further, development of the learning society is also based on the proactive partnership approaches of various networks which are willing to organise lifelong learning activities. Those networks hold the right to and responsibilities in organising lifelong learning. Meanwhile, a holistic and integrated approach should also be applied in order to create a balance in organising lifelong learning activities. Learning should be integrated with citizens' ways of life and it should address different needs of different target groups as well as the social conditions of each target group. Finally, curricula should be adjusted to be in line with the changes in economy, society, politics, administration and environment in order to develop the nation in a sustainable way (Charungkaittikul et al. 2013).

\section{The Office of Non-Formal and Informal Education (ONIE)}

Lifelong learning is one of the key factors for transforming a society into a learning society, with non-formal and informal types of education being considered critical sub-sectors for ensuring opportunities for lifelong learning to all Thai people. In this regard, major areas of focus of the Ministry of Education's Office of NonFormal and Informal Education (ONIE) have been: (1) provision of functional literacy; (2) general non-formal education (secondchance education for those who were unable to complete formal schooling); (3) non-formal vocational and technical training for practical skills and (4) provision of non-formal education for preschool children. On average, over 3,500,000 learners are involved in non-formal and informal education each year (UNESCO 2011). ONIE is the central organisation in promoting the support and coordination of non-formal and informal education. It makes recommendations for policies, plans and strategies, promotes collaboration among individuals and organisations for network agents, and also monitors, inspects and evaluates implementation and so on. There are other government departments and ministries which have been carrying out non-formal education activities, such as the Ministry of Labour through regional institutions and provincial skill-training centres. Private voluntary agencies and various foundations have been involved in the organisation of non-formal education as well, as have industrial factories which organise non-formal education programmes for their employees (ibid.).

In order to transform Thai society into a learning society, efforts should be made to engage the Thai people in intellectual development in tandem with moral development. This enhances 
knowledge, opportunities and occupational security at all stages of life. Thailand is in transition from a rural to an urban society. As a result of the compartmentalised development of urban and rural areas, there is an imbalance between rural and urban communities. In addition to inequalities in terms of economic background and infrastructure there are unequal opportunities to access knowledge and learning resources, exclusive public services and information technology systems. Computer networks used for the transfer of knowledge do not cover all parts of the country. There remain a great number of Thai people who are not appropriately educated and are without means to pursue knowledge (Pongpaiboon 2007). Most agencies in Thailand have simply adopted the guidelines established by the Thailand Knowledge Management Institute (KMI) 4 the Thailand Productivity Institute and 27 agencies/communities recognised as model learning societies across the country (OEC 2008). These guidelines have been formulated without clearer directive frameworks towards a learning society and appropriate learning activities and resources.

Moreover, a recent study (Charungkaittikul et al. 2013) evaluated the operational implementation of non-formal and informal education in Thailand based on the Non-Formal and Informal Education Promotion Act (ONIE 2008). The results showed that ONIE is a key agency in charge of promoting learning among the people. ONIE oversees: (1) 77 educational agencies; (2) 927 non-formal and informal education centres both in provincial and Bangkok areas; and (3) 35 education institutes. In addition to the aforementioned entities, ONIE also heads 7,403 provincial and sub-district non-formal and informal education centres as well as 1,340 community learning centres nationwide. Moreover, ONIE also provides education for hill-tribe citizens at "Mae Fah Luang" Hill-tribe Community Learning Centres, both in the areas under the patronage of His Majesty the King and Her Majesty the Queen and in general areas. Hence, ONIE oversees a total of 10,895 educational agencies managing education for people (ONIE 2011a). The large number of its subordinate offices implies that ONIE bears huge responsibilities. This is also reflected in the large number of students in primary, secondary as well as diploma levels in the non-formal education system and the basic education level, which amounted to $1,288,583$ students. ONIE's major target group includes workers aged $15-59$ as well as senior citizens (ONIE 2011a).

However, ONIE has had to face a number of challenges, including problems concerning transfers of study results (recognition of prior learning) among the formal, informal and non- 
formal systems; a large number of people in the target groups; varieties of learning needs and the lack of a complete and up-todate database system for learners, education managers and supporters. Moreover, education personnel focus on roles and responsibilities of education managers rather than on supporters, e.g., partnership networks. As a result, some supporter networks are neither motivated nor do they have a clear understanding about their roles and responsibilities (ONIE 2011b). It is stated in the 15-year National Education Plan (2002-2016) that there are a number of problems with regard to lifelong, nonformal and informal education. For example, the curricula remain unable to meet the demands of the targeted groups; moreover, the learning results of the learners remain below standard (OEC 2008).

Consequently, policies about non-formal and informal education have been gradually developed. ONIE is the main agency managing such non-formal education based on its well-designed plans. It is clear that Thailand's non-formal and informal education is geared towards several goals: (1) transforming the Thai society into a learning society helping to drive the country's economy and society; (2) giving the people lifelong learning opportunities; (3) allowing all parts of society to have the rights and responsibilities to manage lifelong learning; and (4) promoting lifelong learning as the education management tool for life and society to meet the needs of target groups and integrating such learning with the way of life of all members in the society.

Moreover, the National Education Act (RTG 1999) and its amendment (RTG 2002) also declare principles of education management to provide the Thai people with lifelong learning. At present, there is an attempt for the country to reform the NonFormal and Informal Education Promotion Act (ONIE 2008) towards promoting a Lifelong Education Promotion Act. Such laws ensure that non-formal and informal education are so effectively managed that all people have opportunities to learn and thus develop their potentials. Thai society can thus eventually be transformed into a learning/knowledge society, leading to development and advancement of the country and its human resources.

\section{Learning society best practices in Thailand}

The Office of the Education Council (OEC) compiled an analysis and synthesis of 27 learning communities (OEC 2008). Besides consulting this research study, we also reviewed and analysed a 
summary of the development of ten pilot lifelong learning communities designated by ONIE (ONIE 2009)). We discovered that communities which were regarded as learning communities featured a wide variety of characteristics. While their general characteristics, background, knowledge, partnership approaches, participation in networks and developing process into learning societies were all different, they shared some similarities. The findings led to the successful implementation of a learning society development strategy. Successful learning communities featured the following characteristics:

(1) The communities followed clear guidelines on how to transform themselves into learning societies. For instance, they had worked out some community development plans.

(2) The communities organised a series of activities aimed specifically at the promotion of lifelong learning on a regular and continuous basis. Such activities were overseen by directly responsible parties (e.g. community heads, village committees, professional network groups) or learning networks, including provincial/local administrative organisations, non-formal and informal promotion centres, community development offices, health stations, community learning centres, communities' schools, private development organisations or private agencies. On top of that, the communities had continued to improve such activities, and community members willingly cooperated and worked, in harmony, on the development and initiation of various activities benefiting the communities as a whole.

(3) The community members significantly applied their local knowledge or wisdom, including art, local culture, religion, ways of living, sufficiency economy philosophy and agricultural expertise, to the development of their communities.

(4) The communities possessed efficient and knowledgeable working groups who not only worked effectively as a team but also showed an eagerness to work on bringing maximum benefits to their community.

(5) The communities emphasised democracy and good governance as a guideline for developing themselves into peaceful righteous learning societies. In light of this, the communities took the following principles into consideration.

- Justice: Community members seriously followed laws and regulations and always took into account fairness and justice when they did or decided to do things. 
- Ethics: Emphasis was placed on righteousness and good deeds; the communities encouraged their members to develop themselves as well as being honest, sincere, diligent, patient and disciplined while performing lawful professions.

- Transparency: The community committees worked transparently and people could easily access information about the committees' work. The community members had no doubts about the transparency of the committees' work, as the effective internal control processes allowed them to inspect how the committees work.

- Participation: All involved parties in the communities were always granted opportunities to participate in any decision making on various matters. Such decision making was done at the villages' monthly meetings where community members act as members of committees, sub-committees or working groups who share information, express ideas and suggestions, collaborate in planning and organising various learning activities.

- Responsibility: The community members realised their rights and their responsibilities to the society and they were enthusiastic about finding solutions to problems, while respecting their fellow members' different ideas.

- Worthiness: Most communities were effectively managed and the local resources were mainly utilised for the maximum benefit of the communities as a whole.

Furthermore, the successful communities proved to have effectively and clearly decentralised administration where different working groups are clearly divided.

(6) The communities possessed local wisdom and well-respected leaders. These leaders or "wisdom individuals" had clear visions of the development of communities into self-reliant ones where members live prosperously and happily.

(7) The communities had faith in basic social institutions; namely, religion, educational institutions and families, and some of these social institutions were also the centres where the communities' activities were organised. The communities built a concrete learning atmosphere with various learning resources within the community compounds. Some examples of such learning resources included the local ways of life, environment and nature, learning centres and learning resources for a sustainable economy. In addition, different professional groups also enjoyed a series of learning activities. Different forms of knowledge exchanges within and 
across communities, e.g. study field visits to other learning societies, were conduced regularly.

(8) The communities learned from practice and experience while accepting and applying new knowledge. Furthermore, the community members were willing to change or adapt anything which would benefit their community. Finally, if any problems arose, the community members worked together to overcome them and this harmonious relationship brought about new knowledge.

To sum up, these communities were well supported by different partnership networks. Meanwhile, their members always willingly participated in any learning and development activities organised in the communities. In effect, all community members gained knowledge which related to their ways of living and they became self-reliant, while continuing to develop the quality of their own lives as well as that of their fellow members.

\section{Implementation of learning society development activities in Thailand}

Thailand currently aims to create a "Learning Society", so a great number of organisations intend to provide lifelong learning opportunities to the out-of-school population. Wisanee Siltragool (2007) pointed out that the organisations involved in this can be classified into two main groups providing non-formal and informal education. The first group falls under the responsibility of ONIE, while the second group falls under other ministry departments (Offices) in the Ministry of Education and other ministries, e.g. the Ministry of the Interior, the Ministry of Public Health, the Ministry of Agriculture, the Ministry of Industry, the Office of the Prime Minister, the universities, local community administration, the private sector, etc. Besides governmental organisations (GOs), there are non-governmental organisations (NGOs) involved, which provide programmes and activities for the out-ofschool population. Below, we present details of new government projects designed to enhance lifelong learning both at community and national levels.

Examples of projects at the community level

Examples of lifelong learning activities in different learning society best practices 
One of our earlier studies (Charungkaittikul 2011a) revisited 5 best-practice communities ( 3 from among the 27 recognised by the OEC in 2008, and 2 from among 10 ONIE-piloted learning communities): (1) Banyang Community, Prachinburi; (2) Tamrong Sub-district Administrative Organization, Phetchaburi; (3) Ban Chang Lang Community, Trang; (4) Learning model development of Ban Kamplalai, Khonkaen and (5) Sufficiency Economy Learning Community of Ban Jor Charoen, Chiangrai.

As mentioned before, despite different backgrounds and social structures and applying different ways and policies to the development of their learning societies, all of these communities featured similar patterns of coordination and partnership network formations, and all of them also engaged in lifelong learning activities.

These activities were available both in the formal educational system and in nonformal and informal education. Formal education was organised in accordance with the basic education curriculum stipulated by the Ministry of Education. In addition, some local curricula were also completed; for instance, Ban Chang Lang School created a local curriculum, teaching the students about the preservation of natural resources and the environment, and about the ecosystem of intertidal forests, sea grasses and corals. The communities' non-formal and informal learning activities included training sessions designed to educate community members of all ages, ranging from senior citizens to children and youth, in various areas of knowledge. Examples of such activities are the training of local guides to take visitors through the surrounding intertidal forests, and the training by committees of various groups. The training topics depended on the people's genuine interests, such as the activities aimed at urging the youth to participate in environmental preservation (including camping trips); maintaining traditional culture; sharing knowledge about professions, Thai massage and agricultural expertise; activities designed to reduce people's expenses; activities related to household accounting and organic fertiliser production; further study guidance; legal knowledge; social welfare; health and sanitary issues; antidrug campaigns; public awareness; management and leadership techniques etc.

In addition, the communities also regularly organised activities for members to exchange knowledge as well as broadening their vision. Regular field study visits to other model learning communities and occupational training sessions were also made available. On top of that, some knowledge was also provided by local scholars and local teachers. Furthermore, the communities produced some learning materials of their own, e.g., documents, 
Video Compact Discs (VCDs) and leaflets, and promoted learning channels through radio, TV and websites in order to make the learning more interesting. The communities also provided the people with consultations or lectures which interested people, namely speaking techniques, presentation skills, participatory learning techniques, the techniques to manage stages for knowledge exchanges, adult education psychology, etc. In addition, the community also helped solve agricultural problems, such as organising fertiliser production. In light of this, the relevant government agencies offered financial support to fund these activities as well as seeking partnership networks which would support the activities or act as advisors and learning facilitators. ONIE also provided basic education services for community members, who also continued to learn by themselves through conversations and different learning resources and reading materials available in the communities.

Examples of projects at the national level

New project \# 1 - UNESCO "World Book Capital” Bangkok

Thailand is part of the Association of Southeast Asian Nations (ASEAN), a group of ten nations seeking to come together somewhat like the European Union, but each retaining their own currency. The ten member nations are Thailand, Brunei, Laos, Burma, Cambodia, Indonesia, Malaysia, the Phillipines, Singapore and Vietnam. ASEAN representatives concurred that tight global competition in all domains of life requires basic literacy and that reading was essential to national development. They also shared similar concerns over the urgency of access to books and commitment to promoting reading to citizens from all socioeconomic backgrounds, so that ASEAN could become a learning society poised to compete with more developed neighbours such as Japan, China and the Republic of South Korea. In terms of the availability of books and promoting a commitment to reading, both Thailand and Singapore were in fact two of the leading Southeast Asian nations which were highly committed to campaigning about good reading habits to their citizens. The Thai government has made reading a national agenda, with 2009-2018 being declared the decade for promoting reading. Furthermore, UNESCO's designation of Bangkok as the "World Book Capital 2013" has prompted the Thai government to develop and improve public libraries, school and university libraries and libraries at colleges and other learning institutions. 
New project \# 2 - "Smart Book Home" project

Also in 2013, the government, ONIE and other learning network agents encouraged communities to develop their own learning and enhance community lifelong learning within community-based development through the non-formal and informal education promotion centres. These centres are directly responsible for developing an extensive learning society, organising non-formal education activities, promoting values, enhancing the potential of educational personnel, and supporting lifelong learning network agents to create new ways of managing lifelong support relationships with the learners. Besides, each sub-district of Thailand has a learning centre which provides learning opportunities to interested individuals. On top of the activities going on in the community learning centres located in every subdistrict, ONIE launched a new project in 2013 called "Smart Book Home". By establishing "smart book homes" (community libraries) throughout Thailand, this project aims to improve the literacy rate, foster reading and facilitate lifelong learning. It brings the learning resources to all members of each community and enhances equality, fairness and quality in lifelong learning and education In addition, various state and private agencies also play key roles in holding lifelong learning activities. They include agencies of Subdistrict Administrative Organization, temples, workplaces, local educational administrations or community committees in cooperation with other organisations.

New project \# 3 - Non-formal Education Equivalency Programme (NFE EP) for the recognition of prior learning in adult and community learning

To enhance Thai citizens' chances in the national and international job markets, ONIE also launched the new Non-formal Education Equivalency Programme (NFE EP) for the recognition of prior learning in adult and community learning in 2012. It aims to provide an opportunity for those who have work and life experience but did not complete compulsory studies to obtain basic education at secondary level. It is for the disadvantaged, people who missed or lacked opportunities to access the formal schooling system. Target groups consist of citizens aged $20+$. They are believed to be mature enough, having prior work/life experience of at least 3 years, and able to be responsible for 
themselves in acquiring new knowledge. Learners who pass 50 per cent of the 4 learning modules of 9 subjects will be able to get the evaluation of their practices and experiences. They need a total of 60 credits for theory (core 9 subjects) combined with a practical part to receive their certificate for graduation from secondary-level basic education (Grade 12 or M.6). The whole process takes 8 months. Although this NFE programme is very popular among the out-of school population, the graduation rate is quite low. According to ONIE's implementation report (ONIE 2014), approximately 71,796 participants have registered for the programme since its inception, but only 7,063 have been able to graduate. Society expects quality from the non-formal education graduates. On the other hand, the project helps create the lifelong learning atmosphere in several urban and rural areas in the country. This NFE programme impacts on social and economic development, as well as the lifelong education and learning enhancement for Thai people and society.

Transforming the Non-formal and Informal Education Promotion Act into a Lifelong Education Promotion Act

Besides aiming to build a learning society, the Thai government potentially intends to transform the Non-formal and Informal Education Promotion Act (ONIE 2008) to an envisaged Lifelong Education Promotion Act. The aim is to develop legitimate, standard qualification systems in a long-term process which offer the prospect of portable qualifications which are recognised around the world. However this new Act is still under discussion among expert groups of people and networks.

Higher education institutions such as universities are also committed to work closely with the communities to collaboratively develop new knowledge and innovations, and research the development of the learning society in different community contexts. Creating a learning environment which facilitates the building of a learning society requires something more than a number of educational inputs for the community. Instead, what matters are the ways activities are organised, and how the people as learners are involved. People must not only be recipients of the development, but also active participants in all processes, especially in decision making. The learning activities have to be responsive to the needs of the learners.

Different opinions of the experts in the field from different levels, including policy and operational levels were shared with regard to the national potential transformation of the Non-formal and 
Informal Education Promotion Act (ONIE 2008) into the Lifelong Education Promotion Act.

A workshop to exchange opinions was organised on 15 August 2013 at Chulalongkorn University. The event was held in cooperation between the university's Lifelong Learning Department and ONIE. The group discussion on the topic of "The Potential Transformation of the Non-formal and Informal Education Promotion Act to the Lifelong Education Promotion Act" raised a number of interesting issues; in particular the main question of authority in the imposition of the Non-formal and Informal Education Promotion Act (ONIE 2008).

The conclusion of the strategies for the reform of the NonFormal and Informal Education Promotion Act to be replaced by the Lifelong Learning Promotion Act covered the following aspects: The scope of lifelong education should be made clear and the overall picture of lifelong education should be made broader than national education. It is appropriate to identify definite responsibilities with regard to lifelong education for certain organisations. Nevertheless, there must be a rationale behind the termination of the current Act. With regard to a definition, the group discussion proposed the term "linkage" with a focus on learning about life, Thai ways of life, and the sufficiency principle. In terms of a philosophical dimension, principles for improvement of people's quality of life are particularly emphasised, while the concept about the "ability to think" is still maintained. Learners of all ages should be given equal attention. Non-formal and Informal Education (NIE) centres may act as facilitators as well as a mechanism encouraging organisations and partnership networks to take part in learning activities and education management. As for personnel, both their numbers and their knowledge need to be increased.

To move this forward, the Ministry of Education has allocated a large amount of money to the project as a whole, but NIE centres receive insufficient funding. With regard to decentralisation, it was suggested that offices at operational levels should be assigned more projects and given more authority. In terms of evaluation, an agency in charge of preventing corruption as well as developing Key Performance Indicators (KPIs) should be established in order to reflect the expected results. In terms of education management, the principle should be that Thai uniqueness and identity must always be maintained. While NIE centres should either manage education themselves or let communities do it, the main guideline is that education should always be accessible and learning materials always available. Learning evaluation should be unique, appropriate and relevant. 
According to a representative from the Council of State, education based on the lifelong education concept, including nonformal and informal education, was already based on the National Education Act (RTG 1999), at a time when ONIE still had division status. When the Non-formal and Informal Education Promotion Act (ONIE 2008) was imposed, ONIE became just an office. ONIE personnel cannot advance in their career. Meanwhile, the budget for ONIE is allocated by the Ministry of Education's Office of the Permanent Secretary. It should be noted that education management by ONIE in district levels involves a number of burdens, e.g., budgeting and human resources. Hence, one preliminary solution is that partnership networks are encouraged to help manage education rather than leaving the responsibilities to ONIE alone. Meanwhile, a representative from the Ministry of Education observed that the problem with the current act concerned the scope of authority as well as the lack of unity in enhancing the organisation. Therefore there are four main dimensions to focus on in further developing the lifelong learning policy: (1) basic information about transformation; (2) legal dimensions; (3) organisational dimensions and policy drivers; and 4 ) education management dimensions (Charungkaittikul et al. 2013).

Further, the Non-Formal and Informal Education Promotion Act (ONIE 2008) has also put an emphasis on access to uninterrupted learning. This leads to proper development of manpower and a knowledge-based society with respect to the economy, the society, the environment, security and quality of life. This is not only consistent with national development strategies but also promotes the establishment of a network of partners working together to make education and lifelong learning available to the people.

With a view to improving lifelong learning and education, more exchanges of information on national policies and practices must be organised, along with proper monitoring and evaluation of their implementation in different dimensions. In addition, cooperation must be further encouraged at national, Thailand, ASEAN, Asian and international levels. Insights from these kind of exchanges can then be incorporated in the national Lifelong Education Promotion Act.

\section{Guidelines for the development of a sustainable lifelong learning society}


To be in line with major changes Thailand may need to make in future, and to progress towards the desired learning society, both local and national development need to pursue the following aspects. The learning society model towards enhancing sustainable lifelong learning development consists of five essential elements: (1) the components of a learning society; (2) the principles for the development of a learning society; (3) the steps in the development process of a learning society; (4) the strategies for the development of a learning society and (5) key success factors. All components comprise details which can really be put into practice (Charungkaittikul 2011a, b).

Nine learning society components

Learning society development is comprised of both social structure and institutional structure towards lifelong learning. Individual learning communities/cities/towns all operate in their own locally appropriate ways but have nine common themes: (1) learners; (2) learning providers; (3) learning resources/institutions; (4) knowledge/ wisdom; (5) lifelong learning activities; (6) learning climate; (7) learning network; (8) knowledge management and (9) learning groups/organisations. In addition, the extra elements which are required for the learning society include community size, community culture and tradition, sharing culture, various groups of people living together, close relationships and socialisation, communication networks, warm family ties and strong community, high quality natural resources and environment, definite development plans and strategies, high respect for the essentials of knowledge and lifelong learning, the development of infrastructure, appropriate community design, IT network systems, creation of community learning innovation, assurance of knowledge society right of citizens, active support of government and agencies, and setting-up of specific agencies.

Ten learning society development principles

The principles which characterise the learning society are informed by the demands of the 21st century, by emergent cutting-edge innovations, and by what we now know about how learning happens. The learning society principles include the concepts of: (1) partnership; (2) participation and collaboration; (3) monitoring and evaluation process; (4) lifelong learning needs; (5) community-based development; (6) knowledge-based community development; (7) variety of lifelong learning activities/knowledge- 
related activities; (8) learning related to life and lifelong learning;

(9) equity process and (10) proactive and continuous process.

The ten-step learning society development process

The steps for developing and transforming a community into a learning society can be realised on both national and local levels. They include: (1) embracing the learning society; (2) setting up a "learning society development committee"; (3) diagnosing the status of the current community; (4) developing a learning society vision and strategies; (5) designing a detailed action plan; (6) integrating partnership collaboration; (7) implementing the developed programmes and activities; (8) carrying out a monitoring and evaluation system; (9) sharing knowledge/lessons learned and (10) promoting and publishing information about communities.

At the national level, the government should support and promote a better grasp of knowledge and understanding of the learning society by coaching community leaders and staff as well as staging an awareness campaign and promoting identification benefits of the learning society to its people.

At the local level, each community needs to embrace the learning society as a value/conceptual framework among its members.

In a recent study (Charungkaittikul 2011a, b), successful learning societies were found to have integrated the "bottom-up approach" to strengthen the community's capacity to determine their values and priorities, and to act on them. Meanwhile other external agencies and organisations can be seen as being partners and facilitators in the developmental processes. In implementing this process, community core groups and members may need to identify the learning society vision and strategies which are appropriate to community development planning within the local government's administrative system, and recognise the needs and interests of different target groups. Consequently, any effort to develop a learning society should ensure the active support and interactive commitment of all the society's sectors. The process needs to engage these five main actors: (1) key individuals; (2) key institutions; (3) core groups; (4) wider interests; and (5) key employers (OEC 2004).

Ten learning society development strategies 
Development of a learning society needs to pursue the following strategies: Strategy 1: development of lifelong learners; Strategy 2: development of learning resources; Strategy 3: development of knowledge and wisdom; Strategy 4: development of appropriate community/city design; Strategy 5: development of a learning community and organisation; Strategy 6: development of knowledge management; Strategy 7: development of a learning climate and knowledge sharing culture; Strategy 8: development of process improvement; Strategy 9: development of infrastructure and learning facilities; and Strategy 10: development of network competencies. (The knowledge and guidelines for each strategy are described in more detail in Charungkaittikul 2011a, b.)

Putting the learning society development strategies into practice involves the following processes:

(1) specifying the objectives for development of a learning society;

(2) identifying responsible organisations or working committees;

(3) seeking cooperation from relevant partnership networks;

(4) proceeding with and managing learning society development projects; and

(5) evaluating the results for future improvement.

Fourteen key success factors

Fourteen key success factors which have been identified (Charungkaittikul 2011a, b) include: (1) capable community leaders; (2) active funds support; (3) various learning networks and partnerships; (4) appropriate community size; (5) definite policy, structure and direction; (6) construction of strategies and implementation plans; (7) appropriate community design; (8) dedicated community members/ volunteer groups; (9) a knowledge sharing culture; (10) close relationships among community members; (11) a variety of learning activities; (12) an infrastructure system; (13) an appropriate IT network system and (14) a learning assurance system.

Towards a sustainable happy and strong society

Apart from these five essential elements of the learning society model, developing a learning society is neither quick nor simple (Ergazakis et al. 2004). It is ongoing and dynamic, and it should be sustainable. Let us emphasise once again that the analysis of the 
current situation; the formulation of a clear and definite learning society plan, vision and strategy; the implementation of knowledge-based development and lifelong learning programmes and activities, and their evaluation-in effect, the results of the successful processes in developing learning communities in Thailand - depend on the participation of key actors, groups and individuals in the communities. It is important to develop: a lifelong learning system, to form a virtuous circle system incorporating: individual development, local economic development, social cohesion, policies aimed at partnership, participation and performance, learning liaison related to local innovative projects, development of models incorporating local characteristics and vision, improvement and expansion of learning community driving structure, construction of a monitoring and evaluation system, cooperative and collaborative relationships, action involving networks, strategies for the future, support for innovation and an adequate infrastructure to support the movement (Carrillo 2006; Choi 2003; McCullough et al. 2003).

The learning society should be freely implemented, in natural ways, by the communities themselves. The learning society model will help enhance learning processes among individuals, groups of individuals and social networks in valuable ways. The model will also lead all parties to reach the existing truth, virtue and goodness, as well as raise the people's ability to freely learn in creative ways. Further, the model will eventually cause ways of thinking, beliefs, social value and learning to be changed in positive ways. Thus, the people will find the right way to live in a good and positive frame of mind which should enable them to overcome any problems and meet overall needs in balanced ways, with sound equilibrium, fairness, sustainability, harmony and happiness.

Considering educational development in Thailand, we think it is likely that many Thai people will have been engaged in quality lifelong learning by 2018 . This should become possible by education reform and systematic learning, based on the following three aspects:

1) Improvement of quality and standard of education amongst Thai people: Under effective education management, this improvement should be made in all areas including learners, educational development, learning resources, environment, curricula and professional systems.

2) Knowledge and learning opportunities: Quality learning and knowledge opportunities among Thai people should be 
enhanced. All people, regardless of gender and age, should be granted opportunities to access lifelong learning channels during their lifetime

3) Participation of all involved parties: All members of society should be encouraged to participate in education management which lays emphasis on human development. Thai people of the new generation are expected to learn by themselves as well as developing pleasurable reading habits. On top of that, they should also be always eager to learn and able to communicate effectively with their fellow citizens. In addition, they should develop critical thinking. They are also expected to be ready to solve any problems within the context of their community. The new generation is expected to be disciplined and ethical. They should possess values and be proud to be Thai. Meanwhile, they should also show great respect to the country's constitutional monarchy. Finally, the young Thai generation should always be able to cope with the changing world.

Meanwhile, the country's education policies also focus on enabling learners at all levels to gain better learning results. Working groups or senior citizens are able to continue learning and accumulate knowledge throughout their lives. With such improved learning results, coupled with accumulated knowledge, people of all ages can enjoy a better quality of life while possessing basic knowledge essential both for living and working effectively. This starts with preschool children who are developed to where they can show abilities and levels of development suitable for their ages; and they should also be prepared for further studies. The disabled, the disadvantaged and those from different cultures should also be educated and provided with quality education. Hence, it is necessary that an organisation or mechanism be established to link all systems in the country, e.g. economy, culture, society, law, etc. so that the country can be developed in systematic ways.

\section{Recommendations}

Recommendations for further development

All groups in the society, i.e. government, local agencies, private organisations, NGOs and communities should be involved in the learning society development as follows: 
(1) The government should set up a national workshop and conference for developing a national learning society driving structure. It should also propose the building of a learning society as a National Agenda, involving the cooperation among social networks, and giving support in policy administrative management and budget.

(2) The government, related organisations and communities should implement the ten learning society development strategies proposed above.

(3) The government should promote and support communities, learning providers and individuals to be able to develop their own learning materials, facilities and lifelong learning activities to enhance community lifelong learning based on community-based development.

(4) Local agencies, government, private organisations, NGOs and communities should develop the learning society network into a partnership for community learning development and the learning society, and enhance the network's capabilities in conducting lifelong learning programmes and activities which serve the needs and interests of the target groups focusing on proactive participation and continuation of the process.

(5) Local agencies should set up a learning society development plan for their own communities within the local government's administrative system by involving community members, the government and other related organisations.

(6) The government should develop a national learning society database to provide the opportunity for people and organisations within the country and other countries to be able to access and acquire essential fundamental knowledge and practices of a learning society.

(7) The local and national educational institutions and communities should collaboratively conduct the introduction of new knowledge and innovation, development of and research on the learning society in different community contexts.

(8) Community committees, local authorities and community members should form a learning society development committee in generating a learning society system by involving community members, the government and other related organisations. 
(9) ONIE should be the main organisation responsible for developing an extensive learning society, promote a value framework, increase awareness of learning society value and enhance the potential of the educational personnel, teachers, adult educators and network agents in particular areas, namely learning society development, knowledgebased development, community lifelong learning, programme development, etc., to create new ways of managing lifelong support relationships with the learner.

(10) All groups must be prepared to invest more time and money into innovative media development, provide more learning areas, and organise lifelong learning programmes and activities in the communities. Employers and unions should encourage their staff, members and communities to take advantage of learning opportunities, and provide funding and rewards for doing so. Individuals must be prepared to share their knowledge and experience among people though various learning resources.

(11) The organisations involved, e.g., local agencies, government, private organisations, NGOs and communities should construct an authentic learning society monitoring and evaluation system, with emphasis on an authentic assessment and evaluation in real-life situations and contexts.

(12) International organisations and social investors should lead governments and businesses in a long-term process to develop legitimate, standard qualification systems which offer the prospect of portable qualifications which are recognised around the world.

\section{Conclusion}

As yet the challenges of globalisation do not have the same influence in all countries, and the countermeasures for tackling them differ respectively as well. Thus the focus for learning society development will differ according to the challenges faced by individual nations and local communities.

Thailand has not yet become a "Learning Society". Nevertheless, numerous activities and research studies are being conducted in Thailand (by universities, many other agents of the education system, communities of people who are working and learning together, etc.) which are extremely beneficial to moving Thailand towards becoming a Learning Society. There are both old 
and new challenges which need to be addressed, particularly with regard to changing demographics, social infrastructure, economic development, environment and technologies, and maintaining a sense of community in a society which is becoming increasingly individualistic

Therefore, communities need to examine their specific contexts and develop the appropriate planning and implementation of the learning society at various levels from communities, organisations, cities, regions and the world at large. People and systems must be fully prepared to adapt to future changes and reap future benefits by keeping up with globalisation, building resilience, and developing learning societies to enhance the wellness of individuals and society.

At the heart of the learning society is the commitment of all members to a set of values and the system of lifelong learning, and sharing knowledge with its members and others on a regular lifelong basis which enhances the opportunity of all community members to develop their full capacity of knowledge, skills and attitude. In such a society, education is interwoven with social, political and economic sectors (Senesh 1991).

Thailand has been able to sustain her commitments to lifelong learning for the past forty years (Varavarn 2013). This has been achieved by the unceasing efforts both to expand the vision and the coverage and to respond to the changing contexts and demands.

Beginning from a narrow focus on literacy learners, lifelong learning efforts were expanded to provide continuing education for adult graduates. Indigenous learning networks, religious and social institutions, folk art, crafts and cultures were mobilised and revitalised to enrich lifelong learning culture. Through the synergy between formal and non-formal education, lifelong learning principles gradually penetrated the school system and the universities to finally become the cornerstone of the Education Act of 1999 in guiding the reform of the entire education system. Efforts to realise the goal of lifelong learning were not confined to the Ministry of Education, which began as the key player during the initial years. The values of lifelong learning were soon recognised by the powerful private sectors as a means to upgrade their human resource and to reach their client base. With higher levels of educational attainment, expanding coverage of the mass media and the Internet, particularly social media, the population at large presently constitutes the most powerful force behind the directions of lifelong learning efforts. 
It is important to note that even though the term "lifelong education" has been used almost interchangeably with "lifelong learning" in Thailand, there was indeed a definite shift of focus over the years. In the early phases, "lifelong education" had been employed by the education system to provide alternative and continuing education opportunities to compensate for and to complement formal learning.

Transformation towards "lifelong learning" began when the concept gradually influenced curricula and teaching and learning processes in Thailand. From the initial focus on enabling out-ofschool learners to attain formal qualifications, the value of lifelong learning became more and more recognised as means for developing self-directed learning capabilities, strengthening learning organisations and enriching the learning environment beyond the educational system. The transformation was further strengthened by learning activities taking place outside the Ministry of Education, in particular through the work of the private sector, mass media, community groups and the population at large. Through the influences of these new players, the transformation from lifelong education towards lifelong learning has been fully enhanced.

With these lessons learned, as we move on to the future phase of lifelong learning, it is important to reflect on the following key issues.

(1) the roles of the Ministry of Education and the emerging new players for lifelong learning;

(2) the need to monitor the progress of lifelong learning and to formulate strategic policies and plans;

(3) the need to go beyond self-directed learning citizens towards a learning society;

(4) harnessing the strength of technological advancements for lifelong learning; and

(5) the roles of universities in promoting lifelong learning.

Developing new indicators and transforming paradigms

To make lifelong learning a reality, many older indicators for learning and schooling must change and new ones need to be developed. There are many aspects we do not know enough about. There has been very little research in the field of lifelong 
education and learning. Some areas where knowledge is poor are early childhood education, vocational education, the motivation to learn, informal learning and learning at an older age. Following the processes designed to develop a learning society means taking practical steps and can be used as a guideline for all agents involved in organising lifelong learning activities or relevant projects. Since nature, problems and needs in each community vary, each community can flexibly apply the guideline to developing their society into a learning society in different ways according to their individual community contexts. The organisations, agencies and communities involved can follow both the country's existing strategies and their own development plans and strategies. Importantly, all related parties should take into account the principles of developing a learning society and the success factors for each development step.

Once the aforementioned ten strategies of learning society development are followed, individuals, organisations, agencies and communities are expected to eventually change their paradigm of knowledge, skills and learning in positive ways. Such paradigm transformations should finally bring about new ways of living and social values which are favourable for the development of the society as a whole. Thus the development of the learning society is a sustainable way of developing the kind of lifelong learning which will result in a favourable development of people's quality of lives and society. This, in turn, can become a social force driving a positive development of the country's economy and society.

\section{References}

Carrillo, F. J. (2004). Capital cities: A taxonomy of capital accounts for knowledge cities. Journal of Knowledge Management, 8(5), 28-46.

Carrillo, F. J. (Ed.). (2006). Knowledge cities: Approaches, experiences and perspectives. Oxford: Butterworth-Heinemann/Elsevier.

Casey, C. (2006). A knowledge economy and a learning society: A comparative analysis of New Zealand and Australian experiences. Compare, 36(3), 343-357.

Charungkaittikul, S. (2011a). The scenario of a learning society model toward promoting a positive paradigm shift for communities. Unpublished doctoral dissertation, Chulalongkorn University, Bangkok.

Charungkaittikul, S. (2011b). The scenario of a learning society model toward promoting a positive paradigm shift for communities. 
International Journal of Adult Vocational Education and Technology [IJAVET], 2(3), 30-34.

Charungkaittikul, S., \& Henschke, J. (2011). The scenario of a learning society model toward promoting a positive paradigm shift for communities in Thailand. In S. Dudka (Ed.), Proceedings of the 2011 Midwest Research-to-Practice Conference in Adult, Continuing, Extension, and Community Education (pp. 91-97). St. Charles, MO: Lindenwood University.

Charungkaittikul, S., Sujiva, \& S. Pathumchareonwattana, W. (2013). Evaluation of the operational implementation of non-formal and informal education based on the Non-formal and Information Education Promotion Act B.E. 2551 (2008). Bangkok: Rangsri Publishing House.

Choi, S.D. (2003). Changing skills formation and lifelong learning in South Korea. PhD thesis, University of London, London.

Cisco (2010). The learning society. San Jose, CA: Cisco. Accessed 28 July 2014 from http://www.cisco. com/web/about/citizenship/socioeconomic/docs/LearningSociety_WhitePaper.pdf.

Delors, J., et al. (1996). Learning: The treasure within. The report to UNESCO of the International Commission on Education for the Twenty-first Century. Paris: UNESCO.

Dulayakasem, U. (2005). Past/future of non-formal education management. Bangkok: Monitoring and Evaluation Group. The Office of Non-formal Education Administration.

Ergazakis, K., Karnezis, K., Metaxiotis, K., \& Psarras, J. (2004). Towards knowledge cities conceptual analysis and success stories. Journal of Knowledge Management, 8(5), 5-15.

Ergazakis, K., Metaxiotis, K., Psarras, J., \& Askounis, D. (2006). An emerging pattern of successful knowledge cities' main features. In F. J. Carrillo (Ed.), Knowledge cities: Approaches, experiences and perspectives (pp. 3-16). Oxford: Butterworth-Heinemann/Elsevier.

Faris, R. (1998). Learning communities: Cities, towns and villages preparing for a 21st century knowledge-based economy. A Report submitted to the Resort Municipality of Whistler and the Centre for Curriculum, Transfer and Technology, Victoria. Accessed 28 July 2014 from http:// members.shaw.ca/rfaris/docs/learningcities.pdf.

Faris, R. (2006). Learning cities: Lessons learned. In support of the Vancouver Learning City Initiative. Accessed 28 July 2014 from http://members.shaw.ca/rfaris/docs/VLC\%20Lessons\%20Learned.pdf

Faris, J., \& Peterson, W. (2000). Learning-based community development: Lessons learned for British Columbia. Victoria: Ministry of Community Development, Cooperatives and Volunteers.

Gelpi, E. (1985). Lifelong education and international relations. London: CroomHelm.

Henschke, J. (2014). An international perspective on reorienting traditional higher education institutions toward lifelong learning. Paper presented at the fourth international conference on adult education, "Adult 
education in universities: Local and regional perspectives", 27-30 April in lasi, Romania.

IAEC (International Association of Education Cities). (2012). Member cities of the IAEC. Accessed 28 July 2014 from http://www.edcities.org/en/list-of-member-cities/.

Keating, D. P., \& Hertzman, C. (1999). Developmental health and the wealth of nations: Social, biological and educational dynamics. New York: The Guildford Press.

Kwon, I. T., \& Schied, F. M. (2009). Building communities into lifelong learning cities: The case of the Republic of Korea. Accessed 28 July 2014 from www.adulterc.org/Proceedings/2009/proceedings/ kwon_schied.pdf.

Lantz, A., \& Brage, C. (2006). A learning society/learning organization. Accessed March 12, 2014, from F:LearningsocietyArticle.htm.

Laszlo, K. C., \& Laszlo, A. (2007). Fostering a sustainable learning society through knowledge-based development. Systems Research and Behavioral Science, 24(5), 493-503.

Longworth, N. (2006). Learning cities, learning regions, learning communities. Lifelong learning and government. London: Routledge.

Longworth, N., \& Osborne, M. (2010). Perspectives on learning cities and regions. Leicester: National Institute of Adult Continuing Education (NIACE).

McCullough, M. Carolane, R., \& Hetherington, B. (2003). The Victorian Learning Communities Network: "The experience so far". In Communities of learning: Communities of practice. Proceedings of the 43rd annual national conference adult learning Australia, Sydney 27-30 November (pp. 297-311).

Morris, L., \& Cranford, S. (2007). Toward a knowledge society in the context of a knowledge economy: Where will we go and how we get there? A global perspective. In Proceedings of the 2007 Commission on International Adult Education (CIAE) (pp. 137-149). Norfolk, VA: The American Association for Adult and Continuing Education (AAACE).

NESDB (National Economic and Social Development Board). (2011).

Eleventh national economic and social development plan B. E. 25552559 (2013-2017). Bangkok: NESDB. Accessed 28 July 2014 from http://eng.nesdb.go.th/Portals/0/news/plan/eng/THE\%20ELEVENTH $\% 20 N A T I O N A L \%$

20ECONOMIC\%20AND\%20SOCIAL\%20DEVELOPMENT\%20PLAN \%282012-2016\%29.pdf.

OEC (Office of the Education Council). (2004). Learning city. Bangkok: Educational Standards and Learning Development Bureau.

OEC (Office of the Education Council). (2008). Research study on evaluation process of education for learning society promotion. Bangkok: Ministry of Education.

ONIE (Office of Non-formal and Informal Education). (2008). Non-formal and informal education promotion act B.E. 2551. Bangkok: ONIE. 
ONIE (Office of Non-formal and Informal Education). (2009). The Development models of learning resources management of the best lifelong learning communities in 10 pilot provinces. Bangkok: ONIE.

ONIE (Office of Non-formal and Informal Education). (2011a). Performance report of non-formal and information education. Bangkok: ONIE, Office of Permanent Secretary, Ministry of Education.

ONIE (Office of Non-formal and Informal Education). (2011b). Policies and focus on performance of NIE offices for the fiscal year 2012. Bangkok: ONIE

ONIE (Office of Non-formal and Informal Education) (2014). Non-formal education. Bangkok: ONIE. Accessed 28 July 2014 from http://203.147.62.103/en/2013-07-01-07-03-29/policies-strategicplans/ non-formal-education.

Osborne, M., Kearns, P., \& Yang, J. (2013). Learning cities: Developing inclusive, prosperous and sustainable urban communities. International Review of Education, 59(4), 409-423.

Pichayasathit, S. (2001). A learning society for the promotion of lifelong learning. In UNESCO (Ed.), Lifelong learning in Asia and the Pacific (pp. 124-125). Bangkok: UNESCO Bangkok.

Pongpaiboon, P. (2007). Learning society. Accessed 30 March 2014 from http://learners.in.th/blog/ yardnapa2/15632.

RTG (Royal Thai Government). (1999). National education act B.E. 2542. Bangkok: RTG.

RTG (Royal Thai Government). (2002). National education act. Amendment (issue 2) B.E. 2545. Bangkok: RTG.

RTG (Royal Thai Government). (2007). Constitution of the Royal Kingdom of Thailand B E. 2551. Bangkok: RTG.

Senesh, L. (1991). Building a learning society. Accessed 28 July 2014 from http://files.eric.ed.gov/ fulltext/ED355171.pdf.

Sibmeunpiam, N. (2003). Development of a learning city model: A case study of sub-district administrative organizations in Chonburi Province. Educational Journal of Thailand, 1(1), 43-58.

Siltragool, W. (2007). Thailand. Non-formal education. Country profile prepared for the Education for All Global Monitoring Report 2008. Education for All by 2015: Will we make it? 2008/ED/EFA/MRT/ PI/68. Accessed 28 July 2014 from http://unesdoc.unesco.org/images/0015/001555/155581e.pdf.

Su, Y. H. (2007). The learning society as itself: Lifelong learning, individualization of learning, and beyond education. Studies in Continuing Education, 29(2), 195-206.

Sungsri, S. (2005). The development of learning communities/cities for Thai society. Bangkok: Learning policy development group in local wisdom and traveling. Bangkok: Standards and Learning Bureau.

UNESCO (United Nations Educational, Scientific and Cultural Organization) (2005). Towards knowledge societies. UNESCO World Report. UNESCO Publishing. Accessed 28 July 2014 from http:// unesdoc.unesco.org/images/0014/001418/141843e.pdf. 
UNESCO (United Nations Educational, Scientific and Cultural Organization). (2011). UNESCO National Education Support Strategy (UNESS): Thailand. Bangkok: UNESCO.

Varavarn, K. (2013). Lifelong learning in the 21st century: Reflections from the Thai experiences. Paper presented at the first international conference on lifelong learning for all 18 July (LLL2013), Chulalongkorn University, Bangkok.

World Bank (1998). Knowledge for development. World Development Report 1998-1999. New York: Oxford University Press.

Yarnit, M. (1998). Learning towns and cities-survey. London: IdeA publications.

\section{The authors}

Suwithida Charungkaittikul is a fulltime professor in the Non-formal Education Division, Department of Lifelong Education, Faculty of Education, Chulalongkorn University, Bangkok, Thailand. Dr Charungkaittikul has been actively involved in many academic and volunteer activities both at national and international levels. She is an Assistant Dean in Research and Academic Affairs, Faculty of Education, Chulalongkorn University. She has served as an Assistant Secretary General of the Comparative Education Society of Asia (CESA); a Board Member of the Journal of Educational Leadership in Action (ELA), Lindenwood University, USA. Her main interests are in lifelong learning and education and learning society development.

John A. Henschke is Associate Professor of Education and Chair, Andragogy Doctoral Emphasis Specialty, Lindenwood University, St. Charles, MO, USA. He is the 2014 Board of Directors Chair of the International Adult and Continuing Education Hall of Fame (IACEHOF); Visiting Professor, Beijing, China (PRC) Radio and Television University; and Visiting Professor, Chulalongkorn University, Bangkok, Thailand. Dr Henschke has been researching and testing his adult education (andragogical) ideas, working in the USA and 20 other countries since 1970 , and teaching adult educators from 96 countries. He chaired or was a committee member of 94 completed doctoral dissertations in six Universities around the globe. 